\title{
Post-Traumatic Stress Disorder and Medication Adherence: Results from the Mind Your Heart Study
}

\author{
lan M Kronish, MD, MPH${ }^{1}$, Donald Edmondson, $\mathrm{PhD}^{1}$, Yongmei $\mathrm{Li}, \mathrm{PhD}^{2}$, and Beth $\mathrm{E}$ \\ Cohen, MD, MAS 2,3 \\ ${ }^{1}$ Center for Behavioral Cardiovascular Health, Columbia University Medical Center, New York, \\ NY \\ ${ }^{2}$ General Internal Medicine, Department of Veterans Affairs Medical Center, San Francisco, CA \\ ${ }^{3}$ Department of Medicine, University of California, San Francisco, CA
}

\begin{abstract}
Background-Patients with post-traumatic stress disorder (PTSD) are at increased risk for adverse outcomes from comorbid medical conditions. Medication non-adherence is a potential mechanism explaining this increased risk.

Methods-We examined the association between PTSD and medication adherence in a crosssectional study of 724 patients recruited from two Department of Veterans Affairs Medical Centers between 2008 and 2010. PTSD was assessed using the Clinician Administered PTSD Scale. Medication adherence was assessed using a standardized questionnaire. Ordinal logistic regression models were used to calculate the odds ratios (ORs) for medication non-adherence in patients with versus without PTSD, adjusting for potential confounders.
\end{abstract}

Results-A total of 252 patients (35\%) had PTSD. Twelve percent of patients with PTSD reported not taking their medications as prescribed compared to $9 \%$ of patients without PTSD (unadjusted OR 1.85, 95\% CI 1.37-2.50, $P<.001$ ). Forty-one percent of patients with PTSD compared to $29 \%$ of patients without PTSD reported forgetting medications (unadjusted OR 1.90, 95\%CI $1.44-2.52, P<.001)$. Patients with PTSD were also more likely to report skipping medications (24\% versus 13\%; unadjusted OR 2.01, 95\% CI 1.44-2.82, $P<.001$ ). The association between PTSD and non-adherence remained significant after adjusting for demographics, depression, alcohol use, social support, and medical comorbidities (adjusted OR 1.47, 95\% CI $1.03-2.10, P=0.04$ for not taking medications as prescribed and $1.95,95 \%$ CI $1.31-2.91, P=.001$ for skipping medications).

Conclusions-PTSD was associated with medication non-adherence independent of psychiatric and medical comorbidities. Medication non-adherence may contribute to the increased morbidity and mortality observed in patients with PTSD.

\footnotetext{
(C) 2012 Elsevier Ltd. All rights reserved.

Corresponding Author: Ian M Kronish, MD, MPH, Columbia University Medical Center, 622 West $168^{\text {th }}$ Street, PH9-311, New York, NY 10032 Phone: 212-342-1335; Fax 212-342-3431; ik2293@ columbia.edu.

Conflicts of Interest: None

Financial Disclosures: None

Attestation: This manuscript represents original work and is not under consideration for publication elsewhere. All authors had access to the data and a role in writing the manuscript.

Publisher's Disclaimer: This is a PDF file of an unedited manuscript that has been accepted for publication. As a service to our customers we are providing this early version of the manuscript. The manuscript will undergo copyediting, typesetting, and review of the resulting proof before it is published in its final citable form. Please note that during the production process errors may be discovered which could affect the content, and all legal disclaimers that apply to the journal pertain.
} 


\section{Keywords}

Post-traumatic stress disorder; comorbidity; medication adherence

\section{INTRODUCTION}

Post-traumatic stress disorder (PTSD) is a common, typically chronic anxiety disorder with a prevalence of $8-12 \%$ in the general population and $13-31 \%$ in veterans.[1-5] PTSD comes at a profound cost in terms of disabling psychological distress, elevated risk for suicide, and inability to work.[6] A growing body of research also demonstrates that PTSD, in both veterans and civilians, increases the risks and consequences associated with comorbid medical conditions. [7-13] For example, patients with PTSD are at increased risk of recurrent cardiovascular events, $[14,15]$ and among patients with diabetes, those with PTSD have poorer glycemic control and worse prognosis.[16, 17] The mechanisms explaining the associations between PTSD and adverse outcomes from medical illness remain poorly understood.[18]

Medication adherence represents one of the most essential health behaviors for preventing complications from medical conditions. While some studies have shown that individuals with PTSD engage in increased smoking[19] and decreased physical activity[20], far less is known about the impact of PTSD on medication-taking behavior. Studies that have examined medication adherence in PTSD thus far have restricted their analysis to populations with specific medical illnesses that may directly induce PTSD, including acute coronary events and HIV diagnosis.[15, 21] PTSD that develops related to myocardial infarction or HIV may have different associations with medication non-adherence than PTSD due to more general types of traumatic events.

Accordingly, we sought to better understand the relationship between PTSD and medication adherence in a group of outpatients recruited without regard to specific disease status or trauma exposure. We hypothesized that patients with PTSD would have lower rates of medication adherence, even after accounting for depression and other potential confounders.

\section{METHODS}

\section{Patients}

The Mind Your Heart Study is a prospective cohort study designed to examine the association between PTSD and health outcomes. Patients were recruited between February 2008 and June 2010 from outpatient clinics affiliated with two Department of Veterans Affairs (VA) Medical Centers (San Francisco VA Medical Center and the VA Palo Alto Health Care System, California). Patients were excluded if they planned on leaving the area in three years or did not have contact information for follow-up. Potential patients were also excluded if they were unable to walk one block or had a myocardial infarction in the prior six months as a cardiac treadmill test was done for the study and would be contraindicated in these cases. All patients provided written informed consent and appropriate institutional review boards approved the research protocol.

Overall, 1,020 patients were assessed for eligibility. One hundred and four patients (10.2\%) were found ineligible, primarily due to lacking contact information for follow-up ( $\mathrm{n}=82)$. Of the remaining 916 eligible patients, 172 (18.8\%) declined to participate or did not show up for the baseline interview such that 744 patients were ultimately enrolled in the study. Ten patients were excluded from these analyses because they did not complete full PTSD assessments or because the supervising study psychologist had concerns about the accuracy 
of the PTSD diagnosis. Another 10 patients were excluded because they reported not taking any medications, leaving 724 patients for these analyses.

PTSD

We evaluated PTSD with the Clinician Administered PTSD Scale (CAPS) using criteria from the Diagnostic and Statistical Manual of Mental Disorders IV (DSM-IV).[22] The CAPS is the most widely used structured interview for diagnosing PTSD [23, 24] and has excellent test-retest reliability $(\mathrm{r}=0.92-0.99)$ and internal consistency (alpha $=0.80-0.90)$. [24] The CAPS was also used to identify the categories of trauma exposure that were common in patients with PTSD.

\section{Medication Adherence}

We assessed medication adherence using a standardized questionnaire based on the one used to measure adherence in the CARDIA (Coronary Artery Risk Development in Young Adults) study.[25, 26] Cut-points for determining whether someone was non-adherent were chosen according to convention.[25] Overall medication adherence was assessed by asking patients "Overall, in the past month, how often did you take your medications as the doctor prescribed?" Possible responses were less than half of the time, about half of the time, most of the time, nearly all of the time, and all of the time; overall non-adherence was defined as taking medication as prescribed half of the time or less. Forgetting to take medications was assessed by asking "In the past month, how often did you forget to take one or more of your prescribed medications?" Possible responses were never, once in the last month, 2 to 3 times in the last month, about once per week, several times per week, or nearly every day; nonadherence was defined as forgetting medications once per week or more. Deciding not to take medications was evaluated with the question "In the past month, how often did you decide to skip one or more of your medications?" Possible responses were never, once in the last month, 2 to 3 times in the last month, about once per week, several times per week, or nearly every day; non-adherence was defined as skipping medications once per week or more.

\section{Covariates}

We administered a self-report questionnaire to all patients to determine age, sex, ethnicity, income, education, and medical history.[27] We used the Alcohol Use Disorders Identification Test-consumption questions (AUDIT-C), a validated screening questionnaire, to measure alcohol use, and used recommended cut-off scores of 3 for women and 4 for men to identify patients with possible problematic alcohol use.[28, 29] We assessed social support with the validated 12-item Multidimensional Scale of Perceived Social Support (MSPSS).[30, 31] We used the 9-item Patient Health Questionnaire (PHQ-9) to evaluate depressive symptoms. This self-report instrument measures the frequency of depressive symptoms corresponding to the 9 symptom criteria in the DSM-IV. A standard cut-point of $\geq 10$ is used to define depression and has demonstrated excellent validity when compared with a mental health interview with a sensitivity of $88 \%$ and a specificity of $88 \%$.[32]

\section{Statistical Analysis}

We compared differences in characteristics between patients with and without PTSD using $t$ tests or Mann-Whitney U tests for continuous variables and chi-square tests for dichotomous variables. Given the ordinal nature of our medication adherence variables, for our main analyses, we used separate ordinal logistic regression models to evaluate the association of PTSD with the three medication adherence outcomes. These models yield single odds ratios for the association of the predictor variable (PTSD) with each combination of higher versus lower-risk outcome categories (for example, skipping medications nearly every day vs. other 
categories; nearly every day or several times per week vs. other categories; nearly every day, several times per week, or about once per week vs. other categories; etc.). We adjusted for patient characteristics from Table 1 that were associated with PTSD at $P<.20$ using staged models. Covariates included in the final models included sex, depression, alcohol use, social support, and history of hypertension, elevated cholesterol, diabetes, myocardial infarction, or chronic obstructive pulmonary disease. The proportional odds assumption was verified for all models. To determine if there were differences in the strength of the association between PTSD and type of non-adherence (forgetting to take and deciding to skip medications), we transformed the odds ratios for the association between PTSD and non-adherence into rscores and then derived a Z-statistic according to the method recommended by Steiger.[33] For our secondary analyses, we used the pre-defined cut-points to determine whether patients were or were not adherent and then used chi-squared to test for differences in the proportion of patients with and without PTSD who were non-adherent. All statistical tests were two-sided with $a=0.05$. We used Stata version 11 (StataCorp; College Station, Texas) to perform all analyses.

\section{RESULTS}

Of the 724 patients analyzed, 251 (35\%) had PTSD. The mean age of patients was 58 years, $6 \%$ were women, and 58\% self-identified their race as white. Among patients with PTSD, the most common types of trauma exposures were combat-related (55\%), sexual assault (12\%), physical assault (8\%), non-combat military trauma (3\%), accident (2\%), and unexpected death of close friend or relative (2\%). Compared to patients without PTSD, those with PTSD were more likely $(P<0.05)$ to be female, to have depression, to have lower social support, and to have at-risk alcohol use (Table 1). Patients with PTSD also had higher rates of several comorbid chronic medical conditions.

In unadjusted analyses, patients with PTSD had nearly twice the odds of not taking their medications as prescribed as compared to patients without PTSD (Table 2). The association between PTSD and this measure of medication adherence remained significant even after controlling for potential confounders, including demographics, depression, alcohol use, and medical comorbidities (adjusted OR for overall decreased adherence 1.47, 95\% CI 1.03 $2.10 ; P=0.04)$.

As compared to patients without PTSD, patients with PTSD were also more likely to report forgetting their medications and skipping their medications (Figure). In fully adjusted regression analyses, there was a stronger association between PTSD and deciding to skip medications (adjusted OR 1.95, 95\% CI 1.31-2.91; $P=0.001$ ) as compared to PTSD and forgetting medications (adjusted OR 1.32, 95\% CI $0.95-1.83 ; P=0.09$ ), and the difference in these adjusted ORs was statistically significant $(P<0.001)$.

\section{CONCLUSIONS}

We found that PTSD was associated with lower medication adherence in our sample of 724 patients, even after controlling for depression and other potential confounders. In addition, we found that patients with PTSD were more likely to report forgetting and deciding to skip their medications. This establishes PTSD as an independent risk factor for medication nonadherence in patients recruited from general medicine clinics and expands upon prior studies in this area.

Prior investigators have shown that PTSD was associated with lower adherence to medications prescribed for specific medical illnesses. For example, Shemesh and colleagues enrolled 73 patients with a recent history of myocardial infarction and reported that patients 
with PTSD had a higher prevalence of medication non-adherence than patients without PTSD.[15] This analysis, however, was limited by its small sample size and was not adjusted for depression or other potential confounders. In a larger sample, Zen and colleagues showed that PTSD was associated with decreased medication adherence in patients with stable coronary heart disease, however this association did not remain significant after adjusting for depression.[20] PTSD has also been associated with decreased adherence in patients with HIV, but the comorbidity between PTSD and depression was so high in one study that investigators were unable to test whether PTSD was associated with non-adherence independent of depression.[34] In contrast, our study examines the association between PTSD and medication adherence in a broad group of outpatients without any specific medical illnesses and includes sufficient patients without comorbid depression to test the independent association of PTSD and medication adherence.

There are several potential explanations for why we found an association between PTSD and adherence that was independent of depression, whereas others have not. The severity of PTSD may have been higher in this VA population as compared to other samples.[35] In addition, we used the gold-standard psychiatric interview to identify PTSD whereas prior studies utilized briefer survey measures or interviews. This may have led to more accurate PTSD categorization and more clear delineation between depression and PTSD in our sample.

Currently, most plausible mechanisms to explain how PTSD may influence medication adherence are rooted in PTSD-specific cognitive and behavioral symptoms. Avoidant symptoms are one of the hallmarks of PTSD and patients with PTSD may not adhere to medical treatments that remind them of their initial trauma or of their own mortality more generally. ${ }^{15}$ Also, prior work has demonstrated that patients with PTSD may have impairments in cognitive function, ${ }^{37,38}$ and cognitive dysfunction has been linked with medication non-adherence in prior studies.[36] Interestingly, nearly $41 \%$ of patients with PTSD reported regularly forgetting their medications in our study. Accordingly, PTSDrelated deficits in cognitive function may lead to increased unintentional non-adherence.

Compared to non-adherence due to forgetting medications, we found an even stronger association between PTSD and skipping medications. As described above, this could relate to avoidance symptoms in patients with PTSD. However, it is also possible that patients with PTSD after stroke have unfavorable illness beliefs that, in turn, lead to decreased medication adherence. $[37,38]$ For example, PTSD has been associated with a sense of foreshortened future $[39,40]$ and a lack of personal control over the illness that triggered PTSD[41]; these distinct illness representations may lead affected patients to miss preventive medications out of a fatalistic sense that such medications are not worth taking, particularly for asymptomatic conditions like hypertension or hyperlipidemia. Although some researchers have begun to look at the association between PTSD and beliefs about PTSD treatment[42], we could find no published studies that explored beliefs about treatment for medical conditions in patients with PTSD.

Our findings should be interpreted in light of several potential limitations. First, the crosssectional nature of the data prevents us from ascribing causal attributions to the association of PTSD and medication adherence, though reverse causality (medication non-adherence causing PTSD) is less plausible. Second, medication adherence was measured using selfreport and no objective measures of adherence were available to confirm responses. Nevertheless, self-report measures are often highly correlated with objective measures[43] and have been reliable predictors of poor outcomes in multiple studies.[44, 45] If anything, self-reports may have underestimated the true prevalence of non-adherence in these patients. [46] Third, the study population was majority men and was recruited from VA medical 
centers, which may reduce generalizability. Nevertheless, patients in this study were recruited from general outpatient clinics and included patients with PTSD from a variety of causes. Hence, this study broadens the literature pertaining to the association of PTSD and medication adherence that has previously been restricted to disease-specific or traumaspecific populations.

\section{Summary/Conclusions}

The results of this study suggest that PTSD may be putting patients at increased risk for adverse outcomes from comorbid medical conditions as a result of decreased medication adherence. As depression, socioeconomic status, and medical comorbidities did not explain these associations, future studies should explore other mechanisms, such as differences in beliefs about medications or cognitive dysfunction. In the meantime, clinicians should carefully assess for adherence problems in patients with PTSD.

\section{Acknowledgments}

Funding Support: The Mind Your Heart Study was supported by the National Heart, Lung, and Blood Institute (K23 HL 094765-0), the Irene Perstein Foundation, and Departmental funds from the University of California, San Francisco. Dr. Kronish was supported by the National Heart, Lung, and Blood Institute (K23 HL098359). Dr. Edmondson was supported by grant KM1CA156709 from the National Institutes of Health. The sponsors had no role in the design or conduct of the study, nor in the collection or interpretation of data, nor in the preparation of the manuscript.

We wish to thank the Mind Your Heart Study participants and gratefully acknowledge the contributions of the Mind Your Heart Study staff and co-Investigators, particularly Dr. Mary Whooley.

\section{References}

1. Kessler RC. Posttraumatic stress disorder: The burden to the individual and to society. J Clin Psychiatry. 2000; 61(Suppl 5):4-12. discussion 13-14. [PubMed: 10761674]

2. Kessler RC, Sonnega A, Bromet E, Hughes M, Nelson CB. Posttraumatic stress disorder in the national comorbidity survey. Arch Gen Psychiatry. 1995; 52:1048-1060. [PubMed: 7492257]

3. Boscarino JA. Posttraumatic stress disorder and mortality among u.S. Army veterans 30 years after military service. Ann Epidemiol. 2006; 16:248-256. [PubMed: 16099672]

4. Dohrenwend BP, Turner JB, Turse NA, Adams BG, Koenen KC, Marshall R. The psychological risks of vietnam for u.S. Veterans: A revisit with new data and methods. Science. 2006; 313:979982. [PubMed: 16917066]

5. Friedman MJ. Acknowledging the psychiatric cost of war. N Engl J Med. 2004; 351:75-77. [PubMed: 15229311]

6. Yehuda R. Post-traumatic stress disorder. N Engl J Med. 2002; 346:108-114. [PubMed: 11784878]

7. Beckham JC, Moore SD, Feldman ME, Hertzberg MA, Kirby AC, Fairbank JA. Health status, somatization, and severity of posttraumatic stress disorder in vietnam combat veterans with posttraumatic stress disorder. Am J Psychiatry. 1998; 155:1565-1569. [PubMed: 9812119]

8. Jordan HT, Miller-Archie SA, Cone JE, Morabia A, Stellman SD. Heart disease among adults exposed to the september 11, 2001 world trade center disaster: Results from the world trade center health registry. Prev Med. 2011

9. Wisnivesky JP, Teitelbaum SL, Todd AC, Boffetta P, Crane M, Crowley L, de la Hoz RE, Dellenbaugh C, Harrison D, Herbert R, Kim H, Jeon Y, Kaplan J, Katz C, Levin S, Luft B, Markowitz S, Moline JM, Ozbay F, Pietrzak RH, Shapiro M, Sharma V, Skloot G, Southwick S, Stevenson LA, Udasin I, Wallenstein S, Landrigan PJ. Persistence of multiple illnesses in world trade center rescue and recovery workers: A cohort study. Lancet. 2011; 378:888-897. [PubMed: 21890053]

10. Hoge CW, Terhakopian A, Castro CA, Messer SC, Engel CC. Association of posttraumatic stress disorder with somatic symptoms, health care visits, and absenteeism among iraq war veterans. Am J Psychiatry. 2007; 164:150-153. [PubMed: 17202557] 
11. Jakupcak M, Luterek J, Hunt S, Conybeare D, McFall M. Posttraumatic stress and its relationship to physical health functioning in a sample of iraq and afghanistan war veterans seeking postdeployment va health care. J Nerv Ment Dis. 2008; 196:425-428. [PubMed: 18477887]

12. Ahmadi N, Hajsadeghi F, Mirshkarlo HB, Budoff M, Yehuda R, Ebrahimi R. Post-traumatic stress disorder, coronary atherosclerosis, and mortality. Am J Cardiol. 2011; 108:29-33. [PubMed: 21530936]

13. Pietrzak RH, Goldstein RB, Southwick SM, Grant BF. Physical health conditions associated with posttraumatic stress disorder in u.S. Older adults: Results from wave 2 of the national epidemiologic survey on alcohol and related conditions. J Am Geriatr Soc. 2012; 60:296-303. [PubMed: 22283516]

14. Edmondson D, Rieckmann N, Shaffer JA, Schwartz JE, Burg MM, Davidson KW, Clemow L, Shimbo D, Kronish IM. Posttraumatic stress due to an acute coronary syndrome increases risk of 42-month major adverse cardiac events and all-cause mortality. J Psychiatr Res. 2011

15. Shemesh E, Yehuda R, Milo O, Dinur I, Rudnick A, Vered Z, Cotter G. Posttraumatic stress, nonadherence, and adverse outcome in survivors of a myocardial infarction. Psychosom Med. 2004; 66:521-526. [PubMed: 15272097]

16. Miller SA, Mancuso CA, Boutin-Foster C, Michelen W, McLean-Long C, Foote B, Charlson ME. Associations between posttraumatic stress disorder and hemoglobin a1(c) in low-income minority patients with diabetes. Gen Hosp Psychiatry. 2011; 33:116-122. [PubMed: 21596204]

17. Trief PM, Ouimette P, Wade M, Shanahan P, Weinstock RS. Post-traumatic stress disorder and diabetes. Co-morbidity and outcomes in a male veterans sample. J Behav Med. 2006; 29:411-418. [PubMed: 16865552]

18. Dedert EA, Calhoun PS, Watkins LL, Sherwood A, Beckham JC. Posttraumatic stress disorder, cardiovascular, and metabolic disease: A review of the evidence. Ann Behav Med. 2010; 39:6178. [PubMed: 20174903]

19. Fu SS, McFall M, Saxon AJ, Beckham JC, Carmody TP, Baker DG, Joseph AM. Post-traumatic stress disorder and smoking: A systematic review. Nicotine Tob Res. 2007; 9:1071-1084. [PubMed: 17978982]

20. Zen AL, Whooley MA, Zhao S, Cohen BE. Post-traumatic stress disorder is associated with poor health behaviors: Findings from the heart and soul study. Health Psychol. 2011

21. Vranceanu AM, Safren SA, Lu M, Coady WM, Skolnik PR, Rogers WH, Wilson IB. The relationship of post-traumatic stress disorder and depression to antiretroviral medication adherence in persons with hiv. AIDS Patient Care STDS. 2008; 22:313-321. [PubMed: 18338960]

22. APA. Diagnostic and statistical manual of mental disorders. 4. Washington, DC: American Psychiatric Association; 2000. text revision

23. Blake DD, Weathers FW, Nagy LM, Kaloupek DG, Gusman FD, Charney DS, Keane TM. The development of a clinician-administered ptsd scale. J Trauma Stress. 1995; 8:75-90. [PubMed: 7712061]

24. Weathers FW, Keane TM, Davidson JR. Clinician-administered ptsd scale: A review of the first ten years of research. Depress Anxiety. 2001; 13:132-156. [PubMed: 11387733]

25. Gehi A, Haas D, Pipkin S, Whooley MA. Depression and medication adherence in outpatients with coronary heart disease: Findings from the heart and soul study. Arch Intern Med. 2005; 165:25082513. [PubMed: 16314548]

26. Cutter GR, Burke GL, Dyer AR, Friedman GD, Hilner JE, Hughes GH, Hulley SB, Jacobs DR Jr, Liu K, Manolio TA, et al. Cardiovascular risk factors in young adults. The cardia baseline monograph. Control Clin Trials. 1991; 12:1S-77S. [PubMed: 1851696]

27. Whooley MA, de Jonge P, Vittinghoff E, Otte C, Moos R, Carney RM, Ali S, Dowray S, Na B, Feldman MD, Schiller NB, Browner WS. Depressive symptoms, health behaviors, and risk of cardiovascular events in patients with coronary heart disease. JAMA. 2008; 300:2379-2388. [PubMed: 19033588]

28. Bradley KA, Bush KR, McDonell MB, Malone T, Fihn SD. Screening for problem drinking: Comparison of cage and audit. Journal of General Internal Medicine. 1998; 13:379-388.

29. Bush K, Kivlahan DR, McDonell MB, Fihn SD, Bradley KA. The audit alcohol consumption questions (audit-c): An effective brief screening test for problem drinking. Ambulatory care 
quality improvement project (acquip). Alcohol use disorders identification test. Archives of Internal Medicine. 1998; 158:1789-1795. [PubMed: 9738608]

30. Dahlem NW, Zimet GD, Walker RR. The multidimensional scale of perceived social support: A confirmation study. Journal of Clinical Psychology. 1991; 47:756-761. [PubMed: 1757578]

31. Zimet GD, Powell SS, Farley GK, Werkman S, Berkoff KA. Psychometric characteristics of the multidimensional scale of perceived social support. Journal of Personality Assessment. 1990; 55:610-617. [PubMed: 2280326]

32. Kroenke K, Spitzer RL, Williams JB. The phq-9: Validity of a brief depression severity measure. J Gen Intern Med. 2001; 16:606-613. [PubMed: 11556941]

33. Steiger JH. Tests for comparing elements of a correlation matrix. Psychol Bull. 1980; 87:245-251.

34. Boarts JM, Sledjeski EM, Bogart LM, Delahanty DL. The differential impact of ptsd and depression on hiv disease markers and adherence to haart in people living with hiv. AIDS Behav. 2006; 10:253-261. [PubMed: 16482405]

35. Brinker M, Westermeyer J, Thuras P, Canive J. Severity of combat-related posttraumatic stress disorder versus noncombat-related posttraumatic stress disorder: A community-based study in american indian and hispanic veterans. J Nerv Ment Dis. 2007; 195:655-661. [PubMed: 17700297]

36. Lovejoy TI, Suhr JA. The relationship between neuropsychological functioning and haart adherence in hiv-positive adults: A systematic review. J Behav Med. 2009; 32:389-405. [PubMed: 19291386]

37. Stafford L, Jackson HJ, Berk M. Illness beliefs about heart disease and adherence to secondary prevention regimens. Psychosom Med. 2008; 70:942-948. [PubMed: 18842739]

38. Hekler EB, Lambert J, Leventhal E, Leventhal H, Jahn E, Contrada RJ. Commonsense illness beliefs, adherence behaviors, and hypertension control among african americans. J Behav Med. 2008; 31:391-400. [PubMed: 18618236]

39. Greenwell AN, Cosden M. The relationship between fatalism, dissociation, and trauma symptoms in latinos. J Trauma Dissociation. 2009; 10:334-345. [PubMed: 19585340]

40. Rodriguez MA, Heilemann MV, Fielder E, Ang A, Nevarez F, Mangione CM. Intimate partner violence, depression, and ptsd among pregnant latina women. Ann Fam Med. 2008; 6:44-52. [PubMed: 18195314]

41. Wikman A, Molloy GJ, Randall G, Steptoe A. Cognitive predictors of posttraumatic stress symptoms six months following acute coronary syndrome. Psychol Health. 2011; 26:974-988. [PubMed: 21500103]

42. Spoont M, Sayer N, Nelson DB. Ptsd and treatment adherence: The role of health beliefs. J Nerv Ment Dis. 2005; 193:515-522. [PubMed: 16082295]

43. Krousel-Wood M, Islam T, Webber LS, Re RN, Morisky DE, Muntner P. New medication adherence scale versus pharmacy fill rates in seniors with hypertension. Am J Manag Care. 2009; 15:59-66. [PubMed: 19146365]

44. Gehi AK, Ali S, Na B, Whooley MA. Self-reported medication adherence and cardiovascular events in patients with stable coronary heart disease: The heart and soul study. Archives of Internal Medicine. 2007; 167:1798-1803. [PubMed: 17846400]

45. Rasmussen JN, Chong A, Alter DA. Relationship between adherence to evidence-based pharmacotherapy and long-term mortality after acute myocardial infarction. JAMA. 2007; 297:177-186. [PubMed: 17213401]

46. Shi L, Liu J, Koleva Y, Fonseca V, Kalsekar A, Pawaskar M. Concordance of adherence measurement using self-reported adherence questionnaires and medication monitoring devices. Pharmacoeconomics. 2010; 28:1097-1107. [PubMed: 21080735] 


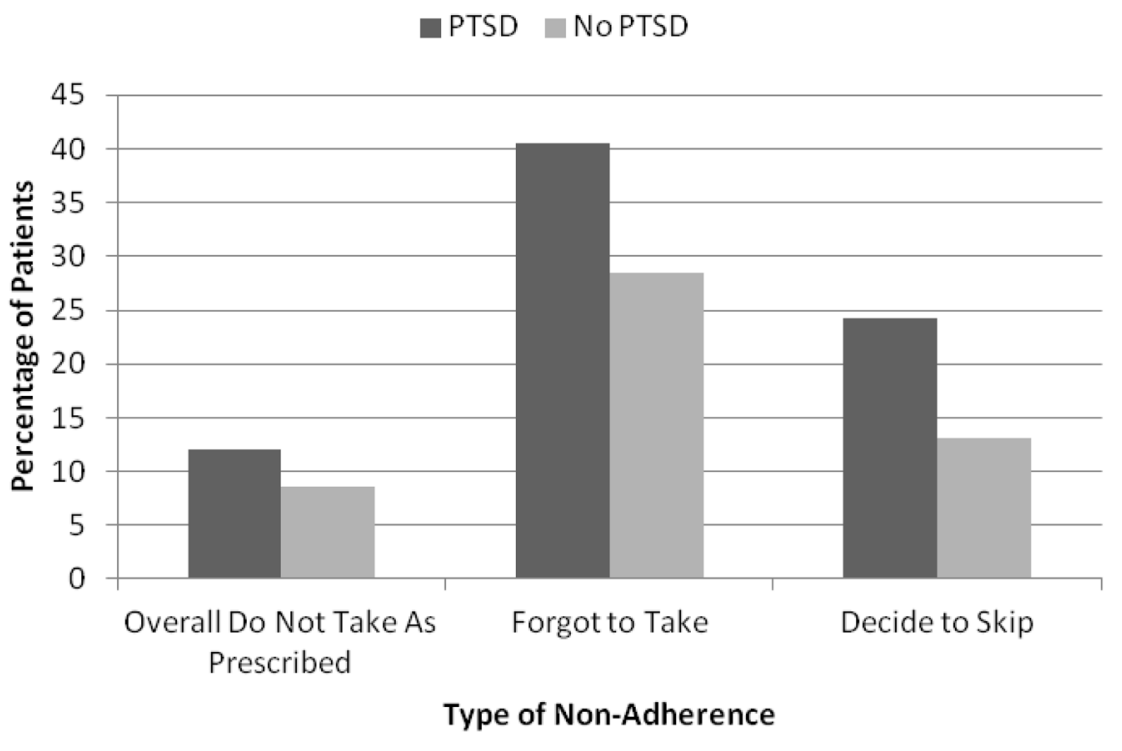

Figure.

Percentage of Patients With and Without Post-Traumatic Stress Disorder Who Are NonAdherent to Medications

Abbreviations: PTSD, Post-Traumatic Stress Disorder 
Table 1

Characteristics of 724 Study Patients According to Post-Traumatic Stress Disorder Diagnosis

\begin{tabular}{lccc}
\hline Characteristic & No Current PTSD N=473 & Current PTSD N=251 & P value \\
\hline Demographics & & & \\
Age, mean (SD), in years & $58.7(12.0)$ & $57.9(10.2)$ & 0.57 \\
Female sex & $14(3.0)$ & $26(10.4)$ & $<0.001$ \\
White race & $272(58.2)$ & $149(61.1)$ & 0.47 \\
Annual income $<\$ 20,000$ & $157(33.4)$ & $71(28.4)$ & 0.17 \\
College graduate & $143(30.3)$ & $71(28.3)$ & 0.57 \\
Psychosocial & & & \\
Depression (PHQ-9 $\geq 10)$ & $70(14.8)$ & $150(59.8)$ & $<0.001$ \\
MSPSS social support score, mean (SD) & $43.5(12.2)$ & $36.5(12.5)$ & $<0.001$ \\
At-risk alcohol use (AUDIT-C $\geq 3$ in women, $\geq 4$ in men) & $207(44.7)$ & $88(36.4)$ & 0.03 \\
Medical History & & & \\
Hypercholesterolemia & $233(49.4)$ & $144(57.4)$ & 0.04 \\
Hypertension & $222(46.9)$ & $149(59.4)$ & 0.001 \\
Chronic obstructive pulmonary disease & $77(16.3)$ & $57(22.7)$ & 0.03 \\
Diabetes mellitus & $73(15.4)$ & $55(21.9)$ & 0.03 \\
Prior heart attack & $41(8.7)$ & $35(13.9)$ & 0.03 \\
\hline
\end{tabular}

Abbreviations: PTSD, Post-Traumatic Stress Disorder; MSPSS, Multidimensional Scale of Perceived Social Support; PHQ-9, 9-item Patient Health Questionnaire; AUDIT-C, Alcohol Use Disorders Identification Test consumption questions

* Data are presented as number $(\%)$ unless otherwise specified 
Ð

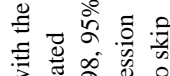

के

के क्ष

응

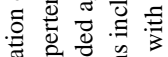

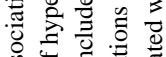

की

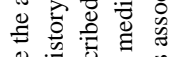

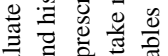

\%

ํ.

웡

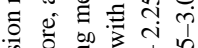

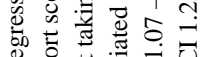

唫

क

要 的

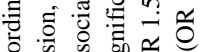

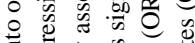

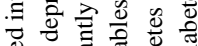

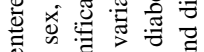

N 